are too numerous to be noticed individually here. Shortly stated, the author has given the benefit of his extensive knowledge and wide experience in the planning, equipment, and arrangement of parks and all their accessories. Every practical expedient that ingenuity can suggest to encourage that open-air life and physical exercise so necessary and beneficial for young and old has been adopted in the schemes and plans submitted by the author of the report.

A word or two about the nature palace may not be out of place. This very important building has been designed to serve several different purposes, such as a winter garden adapted to receptions and conversaziones, and it also could be used as a promenade and popular assembly room, and as a centre for bazaars, periodic industrial exhibitions, flower shows, \&c. The author further proposes to give this building the additional and educational interest of a great museum-a museum which, however, should not aim at having a large general collection of geological, botanical, zoological, and anthropological material, such as those which already exist in larger cities. Indeed, the author points out that it would be cheaper for the trust to send whole schools to the museums of Edinburgh than to attempt to possess an independent institution containing, say, the sixth best collection of skeletons in Scotland or the like. This museum in the nature palace is to be something apart from any existing type of museum; in the words of the author, "A museum not primarily of geology, botany, natural history, anthropology, and so on, yet the whole of these within the living unity of nature, scene by scene--in short, a museum of geography.", So far as the special requirements of the various natural sciences are concerned, the author recommends as a model the Perth Museum, with its well chosen collection of types.

The latter half of the report, forming book ii., deals with the culture uses of museums and institutes. In this part of the volume, art, music, history, and science are all provided for and suitably housed, with a view not merely to their immediate wants, but ample allowance and provision are made for the future development and expansion of each and every phase of human activity bearing on culture and industry.

In this handsome volume, the author has included a vast amount of detailed information and convincing arguments to show the value of parks, gardens, museums, and culture institutes in the social advancement, education, and well-being of communities.

\section{NATURE'S WAYS.'}

U NLIKE the great majority of works of the same class, this little volume takes no notice of birds, but, as its title implies, is entirely devoted to the lower forms of life which may be met with during rambles in different parts of the country, including both animals and plants. As in the case of his earlier book, all the articles have previously been published in various periodicals and journals; and the opportunity for revision given by their re-publication ought to have enabled the author to correct certain deficiencies in style and expression by which the present issue is disfigured.

For example, on p. 29, Mr. Ward manages to introduce the word " which", three times in the course of a single sentence without the use of any higher stop than a comma. On p. 2 we find an obtrusive instance of the ego et rex meus class; and on p. I72 we are told that occasionally examples of a

1 "Peeps into Nature's Ways; being Chapters on Insect, Plant, and Minute Life." By J. J. Ward. Pp. xviii + 302 ; illustrated. (London :
Isbister and Co., NO. I 848 , VOL. 7 I] certain organism are not uncommonly met with. Again, on p. 204 the reader, owing to the misuse of the pronoun " they," is informed that the jaws of a snail possess neither jaws nor teeth; while in the

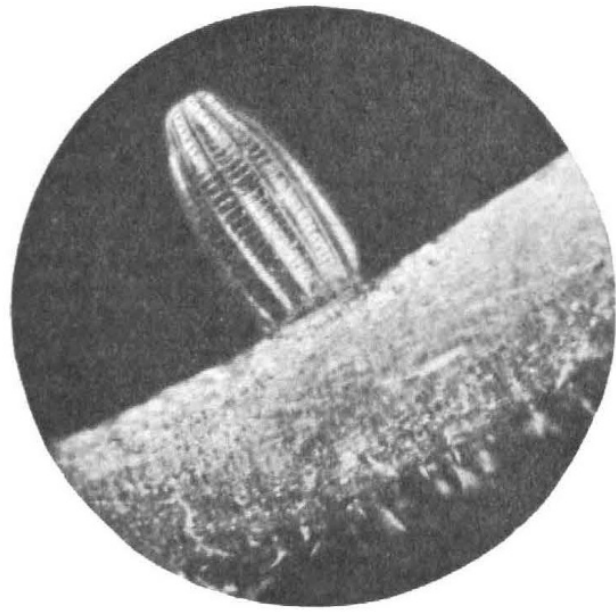

FIG. 1.-Magnified egg of the orange-tip butterfly, on a flower-stalk. From "Peeps into Nature's Ways."

second paragraph on p. 9I we observe a plural pronoun used in connection with a substantive in the singular. The misprint in the first sentence on p. I8I is perhaps excusable; but the statement (p. I86) that

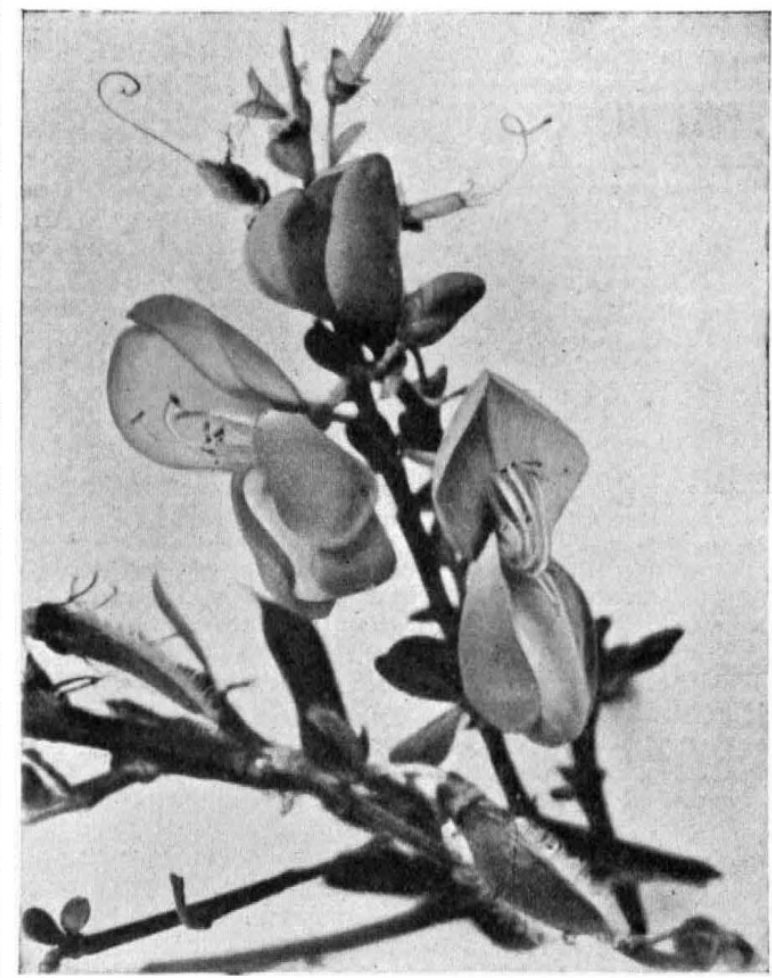

FIG. 2.-A sprig of broom, showing fertilised and "unfertilised flowers. From "Peeps into Nature's Ways."

carbon chemically combines with the water sucked up by plants is scarcely an exact definition of what takes place.

Apart from blemishes like the above, the author may 
be heartily congratulated on his work, which is interesting and readable from start to finish; while the illustrations, reproduced from his own photographs, are in most cases exquisite, as our readers may see for themselves from the two examples furnished herewith. Although he appears to have little or nothing new to record, Mr. Ward is evidently a careful and accurate observer, with the faculty of recording his facts in language that " can be understanded of the people."

With the exception of one chapter on the hydra and a second on the "tongues" of molluses, Mr. Ward's work is restricted to insects and plants. In his opening chapter he details the fascinating life-history of the orange-tip butterfly, showing how its coloration harmonises with the plants it frequents, and how the beautiful green mottling on the hind wings is produced by the blending of dots of black and yellow. As an example of the author's skill in microscopic photography, we reproduce from this chapter his enlarged figure of the egg of the butterfly in question.

Another chapter we have read with special interest is the one on the gorse, in which the author points out how this plant retains evidence of its relationship to the clovers in the form of its seed-leaves; while ht also suggests that the broom may be regarded as in some degree representing a plant in course of evolution to the gorse type, but that its career to this goal has been checked by the fact of its having a bitter taste, which renders its leaves, unlike those of the gorse, uneatable by cattle, so that a protective panoply of spines is superfluous. As a specimen of the author's exquisite photographs of plants, we reproduce the one showing the broom in blossom. Of the other chapters dealing with plants, one is devoted to their hairs and scales, in the course of which the author expresses his belief that he has brought to notice a hitherto undescribed type (in the Auricula); a second chapter is accorded to the sensitive plant, a third to the flowers of woodland trees, a fourth to plant-battles, and a fifth to plants that catch flies.

Reverting to the zoological series, it may be mentioned that the devotion of two chapters to the biographies of a couple of nearly allied species of hawk-moth is perhaps an ill-judged arrangement, as giving too much importance to one group. Be this as it may, the chapter entitled "Living Files and Rasps," in which are described and figured the lingual ribbons of a number of species of gastropods, can scarcely fail to be generally interesting, although it would have been better had the author in every case particularised the genus and species to which his specimens pertain, instead of merely labelling them "snails." In the chapter on mosquitoes and gnats the author does his best to clear up the popular misconception with regard to these insects, and shows how the female, so far as mankind is ooncerned, is the source of all harm and evil.

While, as already stated, it is somewhat marred by errors and inelegances of style, the book as a whole may be pronounced decidedly interesting and attractive, and free from all cant and faddism.

R. L.

\section{GERMAN EDUCATIONAL EXHIBITS AT ST. LOUIS.}

THE German educational exhibit at St. Louis was, as is usual with German exhibits, remarkably complete, and to enhance its value a series of descriptive catalogues was issued. Among the science catalogues were three on scientific instruments, chemistry, and medicine respectively which have special interest for readers of NATURE. They are all on the same plan, and include a general introduction ex- planatory of the scope of the work, and a detailed account of the apparatus, \&c., exhibited. They served a twofold purpose, that of informing visitors to the exhibition as to what there was to see, and also that of bringing together an account of the best products of German workmanship in the respective subjects of the catalogue.

In the catalogue of scientific instruments the introductory description is very full and of real use; special reference is made to novel instruments. Dr. Lindeck, of the Reichsanstalt, who edited the catalogue of the German exhibit in Paris in 1900, is responsible for this, while Dr. Krüss had charge of the section.

The description of the instruments which follows is arranged alphabetically according to the names of the exhibitors. The system of classification with cross references is somewhat less complete than that adopted in the 1900 catalogue, but by aid of the introduction it is easily possible to find any given kind of apparatus. A glance through the catalogue is sufficient to show its utility, and it is to be hoped that the support given to the proposed optical convention and exhibition in May next will be sufficient to justify the committee in issuing a catalogue of English optical goods which will serve the same purpose.

The chemical section at the exhibition contained a reading-room and library, and in this an interesting collection of alchemistic work was shown. Besides these most of the important modern German works on chemistry were to be found on the shelves. Two very interesting exhibits were the alchemistic laboratory, containing partly original apparatus, partly copies of old examples from the museum in Nuremberg, and the Liebig laboratory, a faithful copy of the well-known laboratory at Giessen. The rest of the exhibition illustrated modern chemical apparatus, methods and preparations.

The object of the medical exhibit is said to have been "to show how the German universities deal with the subject of medical instruction," and this was attained by judiciously grouping the articles shown, and by carefully selecting the apparatus. Naturally, various methods are adopted in the different branches; thus, in the department of internal medicine a complete clinical lecture on the diagnosis and therapeutics of tuberculosis is included, the objects required for demonstrating it being exhibited.

Among the apparatus, the microscopes and projection apparatus of Karl Zeiss occupy a prominent place.

It is noteworthy that among the infectious diseases and disease germs tuberculosis comes first.

The catalogue contains a full list of the exhibits with some account of the principal among them, and it is clear that great pains have been taken to secure that the primary object of the exhibition should be carried out.

The three catalogues, in their completeness and orderly arrangement, are examples of the German plan of carrying the teaching and method of science into everyday life.

\section{NOTES.}

THE council of the Linnean Society has appointed a committee to consider the question of zoological nomenclature.

Prof. Lanckrkaux has been elected president for 1905 of the Societé internationale de la Tuberculose.

ThE Canadian Government has decided to place a Marconi wireless telegraph station on Sable Island. The station will come into operation by August I next.

M. PAUL LABBt has been appointed general secretary of the Paris Society of Commercial Geography in success on to the late $\mathrm{Ch}$. Gauthiot. 